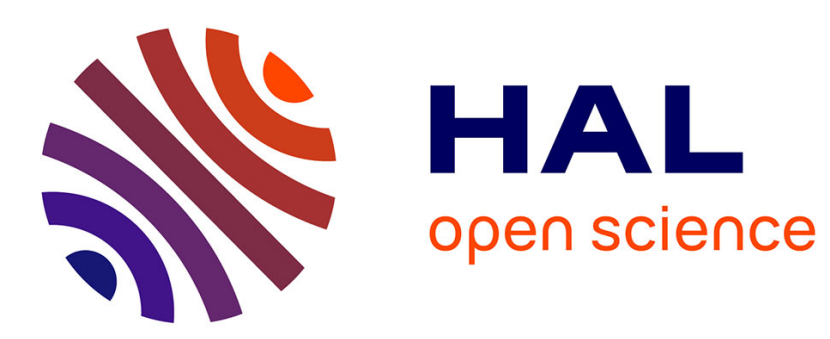

\title{
A new kinetic model for predicting polyamide 6-6 hydrolysis and its mechanical embrittlement
}

Chaker El Mazry, O Correc, Xavier Colin

\section{To cite this version:}

Chaker El Mazry, O Correc, Xavier Colin. A new kinetic model for predicting polyamide 6-6 hydrolysis and its mechanical embrittlement. Polymer Degradation and Stability, 2012, 97, pp.1049-1059. 10.1016/j.polymdegradstab.2012.03.003 . hal-01082759

\section{HAL Id: hal-01082759 \\ https://hal.science/hal-01082759}

Submitted on 14 Nov 2014

HAL is a multi-disciplinary open access archive for the deposit and dissemination of scientific research documents, whether they are published or not. The documents may come from teaching and research institutions in France or abroad, or from public or private research centers.
L'archive ouverte pluridisciplinaire HAL, est destinée au dépôt et à la diffusion de documents scientifiques de niveau recherche, publiés ou non, émanant des établissements d'enseignement et de recherche français ou étrangers, des laboratoires publics ou privés. 


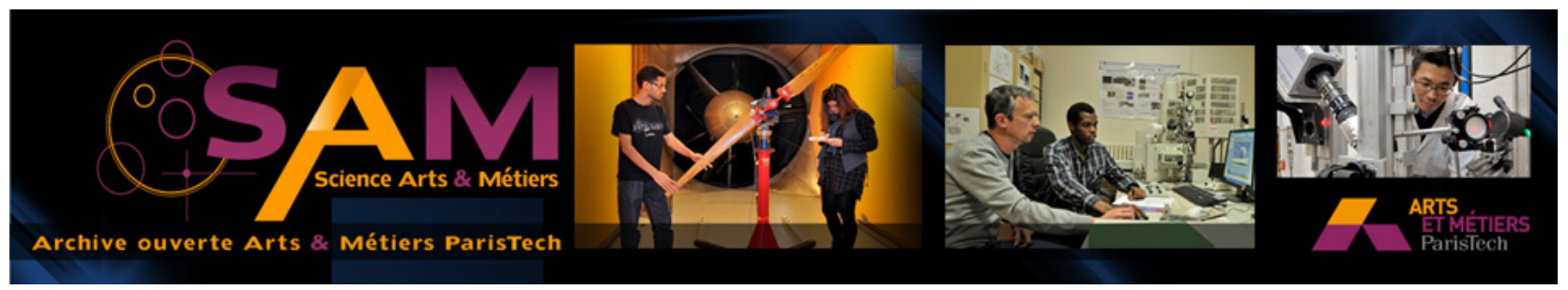

Science Arts \& Métiers (SAM)

is an open access repository that collects the work of Arts et Métiers ParisTech researchers and makes it freely available over the web where possible.

This is an author-deposited version published in: http://sam.ensam.eu

Handle ID: .http://hdl.handle.net/10985/8896

\section{To cite this version :}

CHAKER EL MAZRY, O CORREC, Xavier COLIN - A new kinetic model for predicting polyamide 6-6 hydrolysis and its mechanical embrittlement - Polymer Degradation and Stability - Vol. 97, p.1049-1059- 2012 


\title{
A new kinetic model for predicting polyamide 6-6 hydrolysis and its mechanical embrittlement
}

\author{
C. El-Mazry ${ }^{\mathrm{a}, \mathrm{b}, *}$, O. Correc ${ }^{\mathrm{a}}, \mathrm{X}$. Colin $^{\mathrm{b}}$ \\ ${ }^{a}$ CSTB, Aquasim, 11 rue Henri Picherit, 44300 Nantes Cedex, France \\ ${ }^{\mathrm{b}}$ ARTS ET METIERS ParisTech, Laboratoire PIMM, 151 boulevard de l'Hôpital, 75013 Paris, France
}

Keywords:

Polyamide

Hydrolysis

Chain scission

Chemicrystallisation

Embrittlement

Kinetic modelling

\begin{abstract}
A B S T R A C T
PA 6-6 hydrolysis at 60, 70, 80 and $90^{\circ} \mathrm{C}$ in distilled water has been studied by Fourier transform infrared spectroscopy, viscometry in molten state, differential scanning calorimetry and uniaxial tensile testing. The molar mass decreases sharply from the early periods of exposure to reach an equilibrium value of about $M_{n E} \approx 10-11 \mathrm{~kg} \mathrm{~mol}^{-1}$ almost temperature independent. Hydrolytic chain scissions destroy the entanglement network in the amorphous phase and liberate small macromolecular segments which rearrange locally and initiate a chemicrystallisation. As expected, the embrittlement occurs at a very low conversion of the hydrolysis, in particular when the number average molar mass becomes lower than a critical value of about $M_{n F} \approx 17 \mathrm{~kg} \mathrm{~mol}^{-1}$, i.e. very close to its initial value. A new kinetic model has been derived from the classical mechanistic scheme of reversible hydrolysis. This model describes satisfyingly all the kinetic characteristics of the reversible hydrolysis of PA 6-6 not controlled by water diffusion: decrease in molar mass, increase in crystallinity ratio and decrease in ultimate elongation, but also of other types of polyamides previously studied, such as PA 11. Moreover, when it is used as an inverse method, this model gives access to the rate constants of hydrolysis and condensation reactions. It is thus an interesting tool for elucidating structure/rate constant relationships in common families of hydrolysable polymers.
\end{abstract}

\section{Introduction}

There is an increasing use of polyamides (PAs) for technical applications because of their excellent resistance to mechanical fatigue, friction and many chemical substances (e.g. oils, greases and hydrocarbons), and their high barrier properties to liquids and gases. As an example, PA 11 pipes are currently used for the transport of oil and natural gas in offshore applications. Now, PA 66 and polyphthalamide (PPA) are considered for the elaboration of safety parts in the domestic network of drinking water. However, these materials will be used only if their long term durability, in use conditions, is clearly demonstrated.

It is well known that PAs are very sensitive to moisture. On one hand, they can absorb high amounts of water and thus, undergo an important internal plasticization. As an example, PA 6 and PA 6-6 absorb more than $8 \mathrm{wt} \%$ in 100\% relative humidity (RH) at room temperature [1-3] which reduces their glass transition temperature

\footnotetext{
* Corresponding author. CSTB, Aquasim, 11 rue Henri Picherit, 44300 Nantes Cedex, France. Tel.: +33 144246413; fax: +33 144246382

E-mail address: Chaker.EL-MAZRY-4@etudiants.ensam.eu (C. El-Mazry).
}

of $65-93{ }^{\circ} \mathrm{C}$ [3-6]. On the other hand, PAs undergo a reversible hydrolysis, i.e. a hydrolysis of amide groups which equilibrates, at term, with the reverse reaction of condensation of amine and carboxylic acid end-groups. The resulting reduction in molar mass is responsible for a catastrophic embrittlement of the material [7].

PAs hydrolysis in neutral or acidic water solutions [7-20] and in humid atmospheres [21-23] has been extensively studied at the molecular [8-12,21], macromolecular [7,8,13-19], morphological $[13,19]$ and macroscopic scales $[7,20,22,23]$ since the last half century. It has been the object of specific sections or chapters in handbooks devoted to organic chemistry [24,25], chemical ageing of polymers [26,27] and organic composite materials [28,29], polyamides and their industrial applications [30-33] such as fibres [32] or pipes [33].

From the early 60s, Mikolajewski et al. have observed that the presence of oxygen in a humid atmosphere could accelerate noticeably the overall degradation rate of PAs [34]. But it is only recently that this result has been reconsidered by the scientific community and interpreted as a combination of the effects of thermal oxidation and hydrolysis $[22,23,35]$. Is there a simple additive effect or rather a real coupling between both types of chemical processes? The question is totally open. 
In the case of PA 6-6, however, the effects of oxygen would be significant only at relatively low temperatures close to room temperature $[21,23]$. Through a careful examination of degradation products by ${ }^{17} \mathrm{O}$ NMR spectroscopy, Alam [21] has shown that an almost pure hydrolysis process proceeds between 65 and $125{ }^{\circ} \mathrm{C}$ in $92-96 \% \mathrm{RH}$. In this temperature range, hydrolysis is characterized by a high activation energy of about $87 \mathrm{~kJ} \mathrm{~mol}^{-1}$. More recently, Bernstein et al. [23] have reached the same conclusion. By applying the time-temperature superposition approach to the rate of tensile strength loss between 37 and $138{ }^{\circ} \mathrm{C}$ in $70-100 \% \mathrm{RH}$, they have evidenced the existence of a critical temperature $T_{C} \approx 50{ }^{\circ} \mathrm{C}$ separating two distinct kinetic regimes [23]: Hydrolysis would be predominant above $50{ }^{\circ} \mathrm{C}$ and characterized by a high activation energy of about $93 \mathrm{~kJ} \mathrm{~mol}^{-1}$. On the contrary, thermal oxidation would be predominant below $50{ }^{\circ} \mathrm{C}$ and characterized by a lower activation energy of about $30 \mathrm{~kJ} \mathrm{~mol}^{-1}$. It seems thus possible to determine the respective kinetics of both chemical ageing processes on both sides of $T_{C}$ for PA 6-6.

The aim of the present paper is to outline the main characteristics of a new kinetic model for PAs hydrolysis derived from the classical mechanistic scheme of reversible hydrolysis. The validity of this model will be checked for PA 6-6 from experimental results obtained above $50{ }^{\circ} \mathrm{C}$ in normally oxygenated distilled water, but also for another PA type widely studied previously in the literature: PA $11[17,19]$. This model will be used to attempt to answer an important question: What is the PAs lifetime?

\section{Experimental}

\subsection{Material}

Unstabilised and unfilled PA 6-6 pellets were supplied by Rhodia. Their main characteristics are: melting point $T_{m 0}=266.9 \pm 1.2{ }^{\circ} \mathrm{C}$, crystallinity ratio $X_{C 0}=40 \pm 2 \%$, density $\rho_{0}=1.14 \mathrm{~kg} \mathrm{~m}^{-3}$, weight average molar mass $M_{W 0}=37.3 \mathrm{~kg} \mathrm{~mol}^{-1}$ and molar mass distribution $\mathrm{IP}_{0} \approx 2$.

Prior to processing, pellets were carefully dried at $80^{\circ} \mathrm{C}$ during $72 \mathrm{~h}$ under a primary vacuum in order to prevent hydrolysis at high temperature in molten state. Then, thin PA 6-6 films, of thicknesses ranging from 30 to $100 \mu \mathrm{m}$, were elaborated by compression moulding at $270{ }^{\circ} \mathrm{C}$ under a pressure of $17 \mathrm{MPa}$. They were kept in a desiccator containing silica-gel in order to prevent any moisture uptake before sorption and hydrolytic ageing tests.

\subsection{Ageing conditions and methods of characterization}

\subsubsection{Water sorption tests}

Some PA 6-6 films were exposed to various water vapours (typically between 0 and $90 \% \mathrm{RH}$ ) at $40,50,60$ and $70{ }^{\circ} \mathrm{C}$ in a DVS apparatus (from SMS company, London, England) equipped by an ultrasensitive microbalance of Cahn with an electromagnetic compensation allowing to access to mass changes up to $0.1 \mu \mathrm{g}$. Kinetic curves of water uptake were recorded continuously versus time of exposure. The equilibrium water uptake $[W]_{S}$ was plotted versus relative humidity at each temperature of exposure in order to obtain the classical sorption curves.

\subsubsection{Hydrolytic ageing tests}

Other PA 6-6 films were immersed in distilled water in a glass jar maintained at $60,70,80$ and $90{ }^{\circ} \mathrm{C}$ during some hundreds of hours. Normally oxygenated distilled water was chosen for this study after checking (by introducing a slow nitrogen flow in the water bath) that the effects of thermal oxidation were completely negligible compared to those of hydrolysis.
Films were regularly removed from the jar and dried at room temperature in a desiccator containing silica-gel during, at least, one week. After complete drying, films were characterized by conventional laboratory techniques in order to determine the resulting structural changes at the different pertinent scales (i.e. molecular, macromolecular, morphological and macroscopic scales).

\subsubsection{FTIR spectrophotometry}

After hydrolytic ageing, PA 6-6 films were first analyzed by Fourier transform IR spectrophotometry (Brüker IFS 28 spectrometer, minimal resolution of $4 \mathrm{~cm}^{-1}$ ) between 400 and $4000 \mathrm{~cm}^{-1}$ in a transmission mode. Even after several hundreds of hours spent in distilled water at $90{ }^{\circ} \mathrm{C}$, the conversion ratio of the hydrolysis reaction is clearly too low to induce significant molecular changes in IR spectra. Indeed, it was not possible to detect an increase in the concentration of amine and carboxylic acid endgroups. On the contrary, it was observed an increase in the absorbance of all peaks relative to the crystalline phase and a reduction in the absorbance of all peaks relative to the amorphous phase. These morphological changes were confirmed by differential scanning calorimetry (see below). That is the reason why, in this study, the use of FTIR spectrophotometry was restricted to the determination of the increases in crystallinity according to the following equation:

$X_{C}=\frac{O D_{C}}{O D_{C}+A \times O D_{a}}$

where $X_{C}$ is the crystallinity ratio, $O D_{C}$ and $O D_{a}$ are the respective optical densities of IR peaks relative to the crystalline and amorphous phases, and $A$ is the ratio between the respective molar extinction coefficients:

$A=\frac{\varepsilon_{C}}{\varepsilon_{a}}$

Some IR peaks attributed to the crystalline and amorphous phases and commonly used to determine $X_{C}$ for PAs in the literature [35-46] are reported in Table 1.

Most of them, in particular crystalline peaks located at 906 and $935 \mathrm{~cm}^{-1}$ and amorphous peaks located at 1140 and $1180 \mathrm{~cm}^{-1}$, are directly accessible in IR spectra. As an example, the changes in absorbance against time of exposure of the first three peaks at $80^{\circ} \mathrm{C}$ in distilled water are reported in Fig. 1.

On the contrary, the amorphous peak located at $922 \mathrm{~cm}^{-1}$ is revealed after a deconvolution of the overlapped absorption bands between 880 and $970 \mathrm{~cm}^{-1}$ in the IR spectra. An example of deconvolution is reported for the virgin PA 6-6 in Fig. 2.

Values for the dimensionless constant A were determined so as to recover the crystallinity ratio of virgin PA 6-6. They are reported in Table 2.

\subsubsection{Rheometry}

Then, PA 6-6 films were analyzed by viscometry (TA Instruments ARES rheometer) under nitrogen in molten state, at $265^{\circ} \mathrm{C}$, using a coaxial parallel plate geometry, a plate diameter of $25 \mathrm{~mm}$ and a gap of $1 \mathrm{~mm}$, in order to evaluate the macromolecular changes. Sweep angular frequency experiments were performed in a relatively large frequency domain (typically between 0.1 and $100 \mathrm{rad} \mathrm{s}^{-1}$ ) with a strain amplitude of $5 \%$. These experiments show that the PA 6-6 rheological behaviour is Newtonian in the low frequency range, typically for $\omega \leq 30 \mathrm{rad} . \mathrm{s}^{-1}$. Moreover, as expected in the case of a predominant chain scission process, the Newtonian plateau is a decreasing function of exposure time (Fig. 3). 
Table 1

Examples of IR peaks attributed to crystalline and amorphous phases of PAs in the literature.

\begin{tabular}{|c|c|c|c|}
\hline $\begin{array}{l}\text { Wavenumber } \\
\left(\mathrm{cm}^{-1}\right)\end{array}$ & Assignment & Phase & References \\
\hline 906 & $\mathrm{CH}_{2}$ stretching & Crystalline & $\begin{array}{l}\text { Zimmerman [36] } \\
\text { Holland and Hay [37] } \\
\text { Elsein et al. [38] }\end{array}$ \\
\hline 922 & $\begin{array}{l}\mathrm{C}-\mathrm{C}=\mathrm{O} \\
\text { stretching }\end{array}$ & Amorphous & $\begin{array}{l}\text { Elsein et al. [38] } \\
\text { Hummel [39] } \\
\text { Vasanthan and Salem [40] }\end{array}$ \\
\hline 935 & $\begin{array}{l}\mathrm{C}-\mathrm{C}=\mathrm{O} \\
\text { stretching }\end{array}$ & Crystalline & $\begin{array}{l}\text { Starkweather and } \\
\text { Moynihan [41] } \\
\text { Arimoto [42] } \\
\text { Jakes and Krimm [43] } \\
\text { Murthy et al. [44] } \\
\text { Gonçalves et al. [35] }\end{array}$ \\
\hline 1140 & $\begin{array}{l}\mathrm{C}-\mathrm{O} \\
\text { deformation }\end{array}$ & Amorphous & $\begin{array}{l}\text { Vasanthan et al. [46] } \\
\text { Starkweather and } \\
\text { Moynihan [41] } \\
\text { Jakes and Krimm [43] } \\
\text { Gonçalves et al. [35] }\end{array}$ \\
\hline 1180 & $\mathrm{CH}_{2}-\mathrm{NH}$ & Amorphous & $\begin{array}{l}\text { Vasanthan and Salem [40] } \\
\text { Gonçalves et al. [35] } \\
\text { Thanki and Singh [45] } \\
\text { Vasanthan et al. [46] }\end{array}$ \\
\hline
\end{tabular}
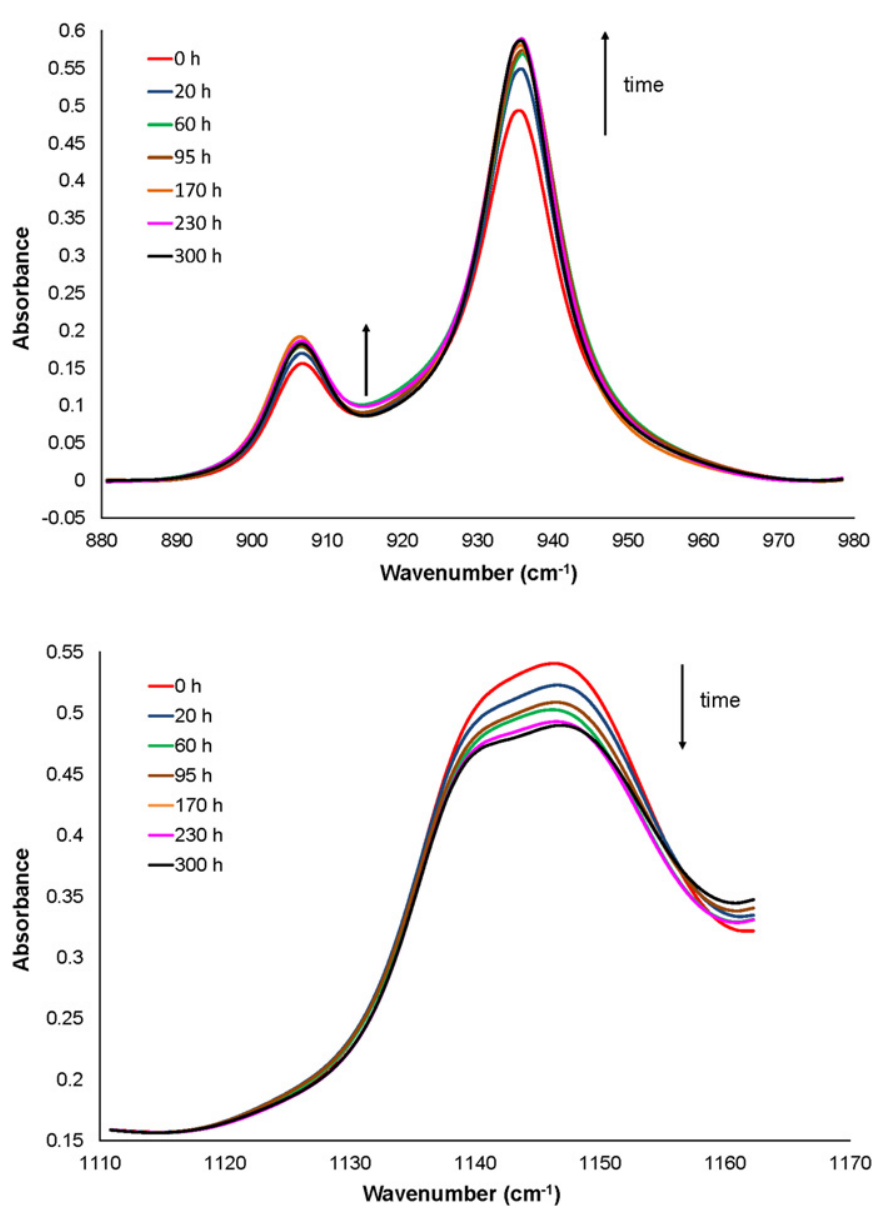

Fig. 1. Changes in the absorbance of IR peaks relative to the crystalline (top) and amorphous phases of PA 6-6 (bottom) at $80^{\circ} \mathrm{C}$ in distilled water. Measurements made on PA 6-6 films of about $45 \mu \mathrm{m}$ thick.

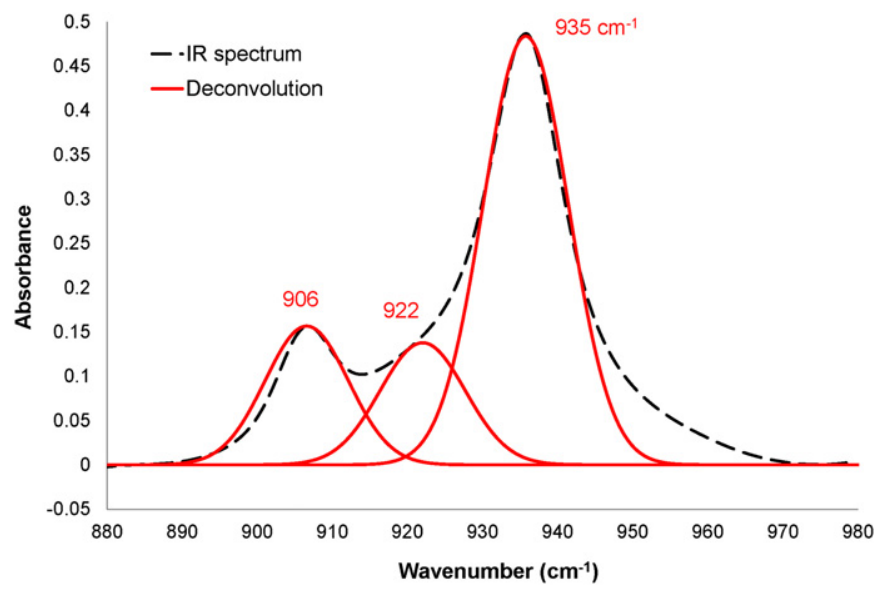

Fig. 2. Deconvolution of the absorption bands overlapped between 880 and $970 \mathrm{~cm}^{-1}$ in the IR spectrum of a virgin PA 6-6 of about $45 \mu \mathrm{m}$ thick. Evidence of a new peak centered at $922 \mathrm{~cm}^{-1}$ and attributed to the amorphous phase of PA 6-6.

Thus, the decreases in weight average molar weight $\mathrm{M}_{\mathrm{W}}$ were determined from the decreases in Newtonian viscosity $\eta$ using the classical Bueche's equation $[47,48]$ :

$\eta=K M_{W}^{3.4}$

where $K$ is a constant depending only on molecular structure and temperature.

$K$ was determined at $265{ }^{\circ} \mathrm{C}$ from the initial values of the weight average molar mass $M_{W 0}=37.3 \mathrm{~kg} \mathrm{~mol}^{-1}$ and the Newtonian viscosity $\eta_{0}=350 \pm 40$ Pa s of PA 6-6 films:

$K=\frac{\eta_{0}}{M_{W 0}^{3.4}}=1.6 \times 10^{-3} \mathrm{~Pa} \cdot(\mathrm{kg} \cdot \mathrm{mol})^{-3.4}$

\subsubsection{Differential calorimetry}

PA 6-6 films were also analyzed by differential scanning calorimetry (TA Instruments Q10 and Q 1000 calorimeters) under nitrogen, between 25 and $300{ }^{\circ} \mathrm{C}$, with an heating rate of $10{ }^{\circ} \mathrm{C} \mathrm{min}^{-1}$, in order to monitor the resulting morphological changes. From the early periods of exposure in distilled water, it can be seen the appearance and growth of a series of secondary melting peaks located between $210{ }^{\circ} \mathrm{C}$ and the principal melting point $T_{m 0}=261.2 \pm 1.3{ }^{\circ} \mathrm{C}$ (Fig. 4). These new peaks are progressively shifted towards higher temperatures and finally join the principal melting peak.

It is thus clear that PA 6-6 undergoes a secondary crystallization during its hydrolytic aging, presumably starting from pre-existing crystal nuclei which are formed during processing but are, unfortunately, practically undetectable by DSC. It is suspected that this secondary crystallization is the direct consequence of hydrolytic chain scission in a PA 6-6 amorphous phase plasticized by water. Indeed, in this case, hydrolytic chain scission would destroy the

Table 2

Values taken for constant $A$ depending on the choice of absorption bands for crystalline and amorphous phases.

\begin{tabular}{llll}
\hline & $906 / 1140 \mathrm{~cm}^{-1}$ & $922 / 935 \mathrm{~cm}^{-1}$ & $935 / 1140 \mathrm{~cm}^{-1}$ \\
\hline $\mathrm{A}$ & 0.57 & 5.10 & 1.31 \\
\hline
\end{tabular}




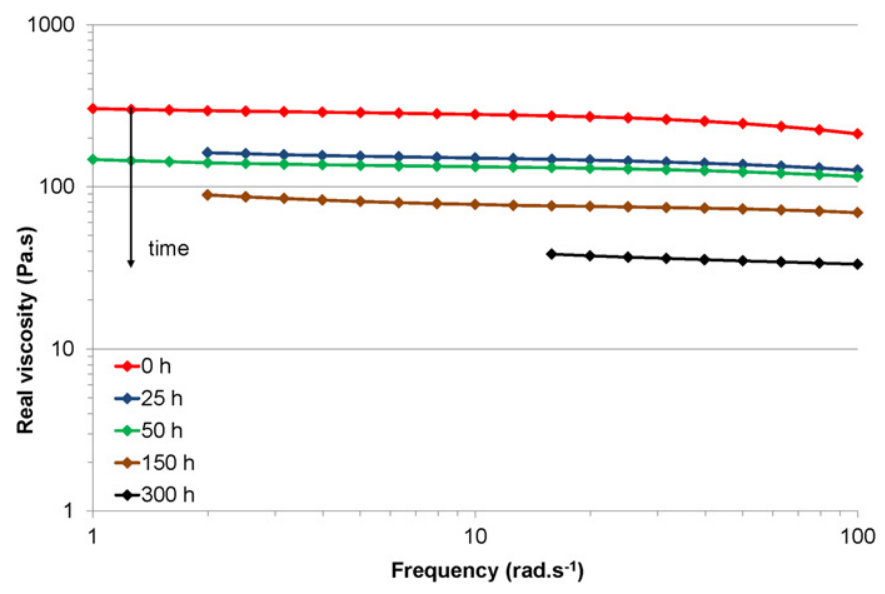

Fig. 3. Curves of dynamic melt viscosity versus angular frequency at $265{ }^{\circ} \mathrm{C}$ after immersion of PA 6-6 at $80{ }^{\circ} \mathrm{C}$ in distilled water.

entanglement network in the rubbery amorphous phase and thus, liberate small macromolecular segments which would self-diffuse to the crystals surface and initiate a chemicrystallisation.

In a first approach, it was assumed that these secondary lamellae present the same physical and thermal characteristics than the initial primary lamellae, i.e. the same surface free energy, density and equilibrium melting temperature. In other words, it was assumed that the secondary lamellae differ from the initial primary lamellae only by a smaller thickness. Then, the global crystallinity ratio was calculated as follows:

$X_{C}=\frac{\sum \Delta H_{m i}}{\Delta H_{m}^{0}}$

where $\Delta H_{m i}$ is the respective area of the different melting peaks and $\Delta H_{m}^{0}$ is the enthalpy of fusion of the crystalline phase.

Value of $\Delta H_{m}^{0}$ was taken in the literature: $\Delta H_{m}^{0} \approx 188.4 \mathrm{~J} \mathrm{~g}^{-1}$ [3].

\subsubsection{Uniaxial tensile testing}

At least, PA 6-6 films were characterized by uniaxial tensile testing (Instron 4310 machine) at $23{ }^{\circ} \mathrm{C}$ and $50 \% \mathrm{RH}$, with a strain rate of $7.5 \times 10^{-3} \mathrm{~s}^{-1}$, in order to evaluate the consequences of both macromolecular and morphological changes on the mechanical behaviour. It was observed that the main modifications of tensile curves take place in the early periods of exposure in distilled water.

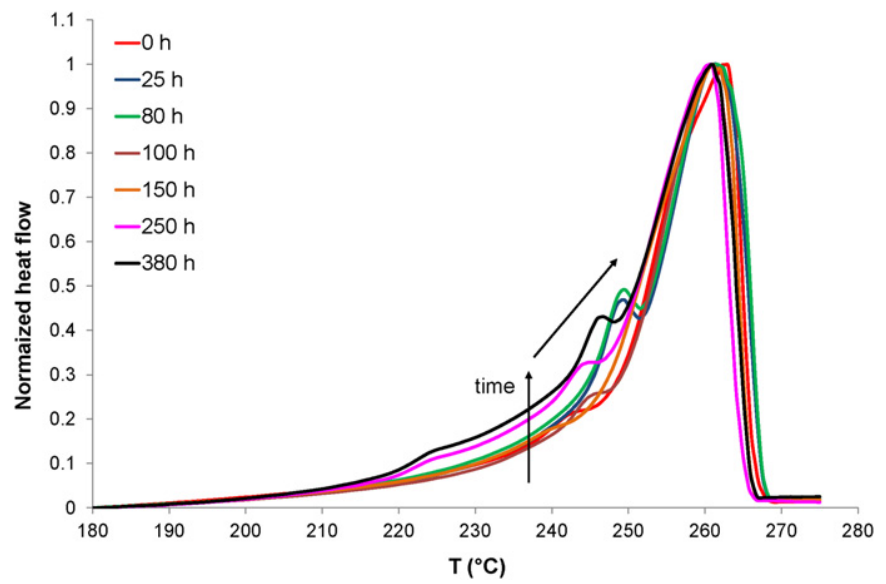

Fig. 4. Curves of normalized heat flow versus temperature after immersion of PA 6-6 at $70{ }^{\circ} \mathrm{C}$ in distilled water.
They consist in the disappearance of the plastic plateau (Fig. 5). Thus, the initially semi-ductile PA 6-6 becomes rapidly brittle and, from that moment, its failure occurs in the absence of necking. That is the reason why, in this study, a peculiar attention was paid on ultimate elongation $\varepsilon_{\mathrm{R}}$ in order to evaluate the embrittlement state of PA 6-6.

\section{Theoretical}

\subsection{Kinetic modelling of reversible hydrolysis}

Let's consider the case of reversible hydrolysis not controlled by water diffusion. The corresponding mechanistic scheme can be written [16]:

$E+W \rightarrow A m+A c \quad\left(k_{H}\right)$

$A m+A c \rightarrow E+W$

In the case of PA 6-6, E, W, Am and Ac designate respectively amide groups, water, and amine and carboxylic acid end-groups. $k_{H}$ and $k_{C}$ are the respective rate constants of hydrolysis and condensation reactions.

A kinetic model can be derived from this mechanistic scheme making a set of four assumptions:

Assumption 1: Equal reactivity of all amide groups.

Assumption 2: Random attack by water of all amide groups.

Assumption 3: Equilibrium water concentration $[W]_{S}$ reached from the early periods of exposure in the case of sufficiently thin PA 6-6 films (for typically thickness lower than $100 \mu \mathrm{m}$ ):

$[W]=[W]_{0}=[W]_{S}$

Assumption 4: Equal initial concentration of amine and carboxylic acid end-groups:

$[A m]_{0}=[A c]_{0}=b_{0}=M_{n 0}^{-1}$

where $M_{n 0}$ is the initial number average molar mass.

The changes in concentration of amide groups are given by:

$\frac{\mathrm{d}[E]}{\mathrm{d} t}=-k_{H}[E][W]+k_{C}[A m][A c]$

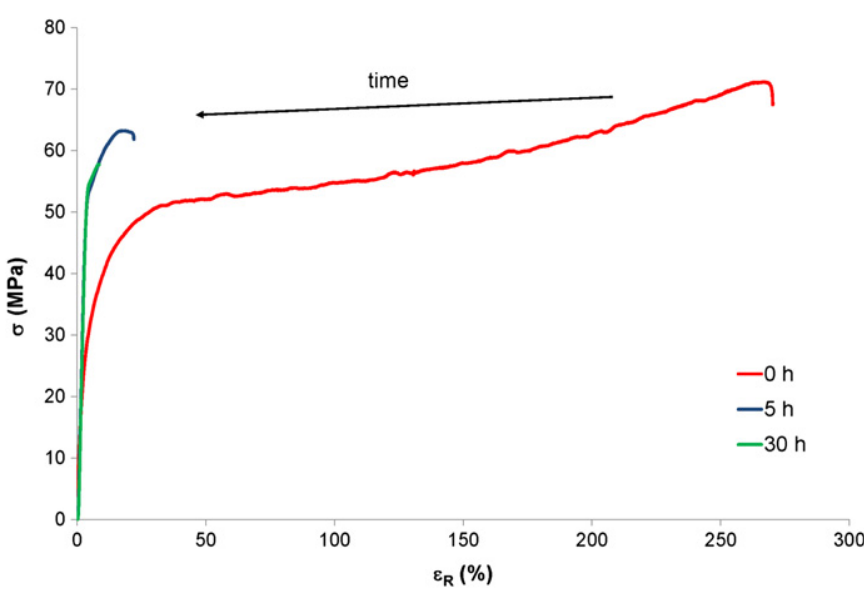

Fig. 5. Tensile curves of PA 6-6 films of about $100 \mu \mathrm{m}$ thick after immersion at $80^{\circ} \mathrm{C}$ in distilled water. 
However, each hydrolysis event leads to the destruction of one amide group by one chain scission. The rate of chain scission is thus given by:

$\frac{\mathrm{d} S}{\mathrm{~d} t}=-\frac{\mathrm{d}[E]}{\mathrm{d} t}$

which leads finally to:

$[E]=[E]_{0}-S$

where $[E]_{0}$ is the initial concentration of amide groups.

Moreover, each chain scission creates one amine and one carboxylic acid end-groups:

$\frac{\mathrm{d} S}{\mathrm{~d} t}=\frac{\mathrm{d}[A m]}{\mathrm{d} t}=\frac{\mathrm{d}[A c]}{\mathrm{d} t}$

which leads finally to:

$[A m]=[A c]=b_{0}+S$

Then, Eqs. 7 and 8 become:

$\frac{\mathrm{d} S}{\mathrm{~d} t}=k_{H}[W]\left([E]_{0}-S\right)-k_{C}\left(b_{0}+S\right)^{2}$

This equation is of the general mathematical form:

$\frac{\mathrm{d} S}{\mathrm{~d} t}=-k_{C}\left(S^{2}+\lambda S-\mu\right)$

where:

$\lambda=\frac{k_{H}[W]+2 k_{C} b_{0}}{k_{C}}$

and

$\mu=\frac{k_{H}[W][E]_{0}-k_{C} b_{0}^{2}}{k_{C}}$

The corresponding equation of second degree: $S^{2}+\lambda S-\mu=0$ admits two roots (one positive $S_{1}$, other negative $S_{2}$ ) of which the corresponding expressions are given by:

$S_{i}=\frac{-\lambda \pm \sqrt{\lambda^{2}+4 \mu}}{2}$

i.e. $S_{1}=\frac{\lambda}{2}\left\{-1+\left[1+\frac{4 \mu}{\lambda^{2}}\right]^{1 / 2}\right\}$

and

$S_{2}=-\frac{\lambda}{2}\left\{1+\left[1+\frac{4 \mu}{\lambda^{2}}\right]^{1 / 2}\right\}$

Of course, only the positive root $S_{1}$ has a physical sense. It corresponds to the maximal value of $S$ when $t \rightarrow \infty$. As a result, it can be written, at any time:

$S \leq S_{1}$
Finally, Eq. 13 can be rewritten:

$\frac{\mathrm{d} S}{\left(S-S_{1}\right)\left(S-S_{2}\right)}=-k_{C} \mathrm{~d} t$

The integration of this equation, between 0 and $t$, leads to:

$\frac{1}{S_{1}-S_{2}} \operatorname{Ln}\left|\frac{S-S_{1}}{S-S_{2}}\right|=-k_{C} t+A$

i.e. $\operatorname{Ln}\left[\frac{S_{1}-S}{S-S_{2}}\right]=-K t+B$

where $K=k_{C}\left(S_{1}-S_{2}\right)$. $A$ and $B$ are two constants.

However, when $t=0, S=0$. Thus:

$B=\operatorname{Ln}\left(-\frac{S_{1}}{S_{2}}\right)$

Finally, one obtains:

$\operatorname{Ln}\left[\frac{S_{2}}{S_{1}} \frac{S-S_{1}}{S-S_{2}}\right]=-K t$

i.e. $\frac{S-S_{1}}{S-S_{2}}=\frac{S_{1}}{S_{2}} \exp -K t$

i.e. $S-S_{1}=\left(S-S_{2}\right) \frac{S_{1}}{S_{2}} \exp -K t$

i.e. $S\left(1-\frac{S_{1}}{S_{2}} \exp -K t\right)=S_{1}(1-\exp -K t)$

i.e. $S=S_{1} \frac{1-\exp -K t}{1-\frac{S_{1}}{S_{2}} \exp -K t}$

Let's notice that this last equation checks well the following boundary conditions:

- When $t=0, S=0$.

- When $t \rightarrow \infty, S \rightarrow S_{1}$.

By introducing Eq. 28 into Eqs. 9 and 11, it is possible to calculate, at any time, the changes in amide groups and amine and carboxylic acid end-groups:

$[E]=[E]_{0}-S_{1} \frac{1-\exp -K t}{1-\frac{S_{1}}{S_{2}} \exp -K t}$

$[A m]=[A c]=b_{0}+S_{1} \frac{1-\exp -K t}{1-\frac{S_{1}}{S_{2}} \exp -K t}$

\subsection{Problem of uniqueness of rate constants}

The number of chain scissions $S$ appears as a very useful quantity to validate the kinetic model because it can be determined experimentally either by titration of amine or carboxylic acid end- 
groups (see above Eqs. 9 and 11) or by viscometry in molten state (see below Eqs. 36-38).

The changes in $S$ with exposure time display the shape of Fig. 6 . Such a curve can be satisfyingly described by only two values: initial rate of chain scission $v_{S O}$ and maximal number of chain scissions $S_{1}$.

The expression of $v_{S 0}$ can be determined from Eq. 12:

$v_{S 0}=\left.\frac{\mathrm{d} S}{\mathrm{~d} t}\right|_{t \rightarrow 0}=k_{H}[W][E]_{0}-k_{C} b_{0}^{2}$

The expression of $S_{1}$ is obtained by introducing Eqs. 14 and 15 into Eq. 17:

$S_{1}=\frac{k_{H}[W]+2 k_{C} b_{0}}{2 k_{C}}\left\{-1+\left[1+4 k_{C} \frac{k_{H}[W][E]_{0}-k_{C} b_{0}^{2}}{\left[k_{H}[W]+2 k_{C} b_{0}\right]^{2}}\right]^{1 / 2}\right\}$

i.e. $S_{1}=\left(\frac{k_{H}}{2 k_{C}}[W]+b_{0}\right)\left\{-1+\left[1+\frac{4 k_{C}[E]_{0}}{k_{H}[W]} \frac{1-\frac{k_{C} b_{0}^{2}}{k_{H}[W][E]_{0}}}{\left[1+\frac{2 k_{C} b_{0}}{k_{H}[W]}\right]^{2}}\right\}\right.$

One sees that $v_{S 0}$ and $S_{1}$ depends only on three kinetic parameters: water concentration [W] and rate constants $k_{H}$ and $k_{C}$. Thus, the direct determination of one of these parameters, by a complementary analytical technique, will allow us to access to the values of other two by kinetic modelling.

That is the reason why, in this study, we have first determined $[W]$ by water sorption tests before determining rate constants $k_{H}$ and $k_{C}$ using the model as an inverse method.

\subsection{Calculation of the equilibrium water concentration}

Water sorption isotherms of PA 6-6 films at 40, 50, 60 and $70{ }^{\circ} \mathrm{C}$ are presented in Fig. 7. The equilibrium water concentration $[W]_{S}$ has been plotted versus the water activity a in the polymer-water mixture. This latter is related to $\mathrm{RH}$ by:

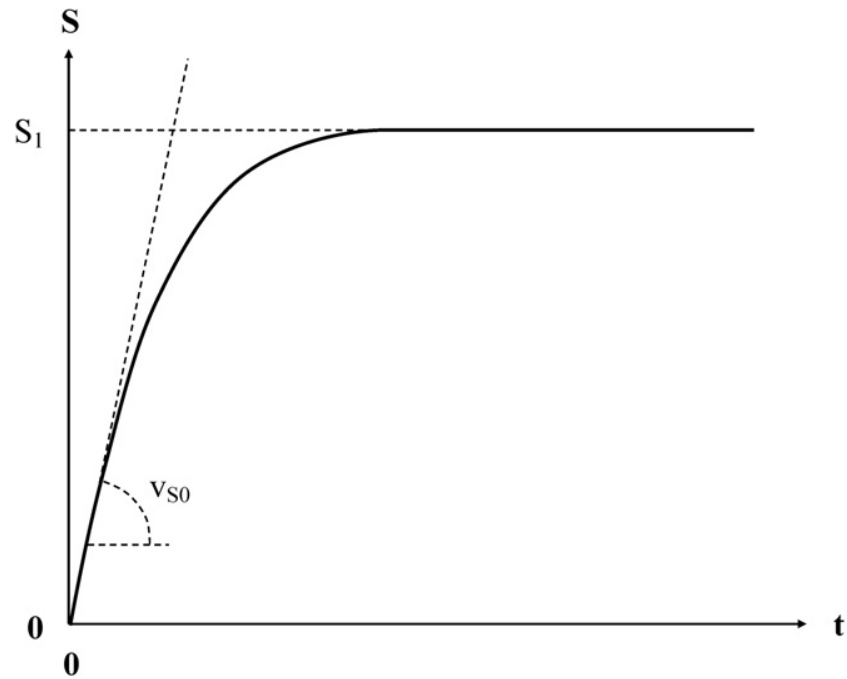

Fig. 6. Schematic shape of kinetic curves of number of hydrolytic chain scissions.

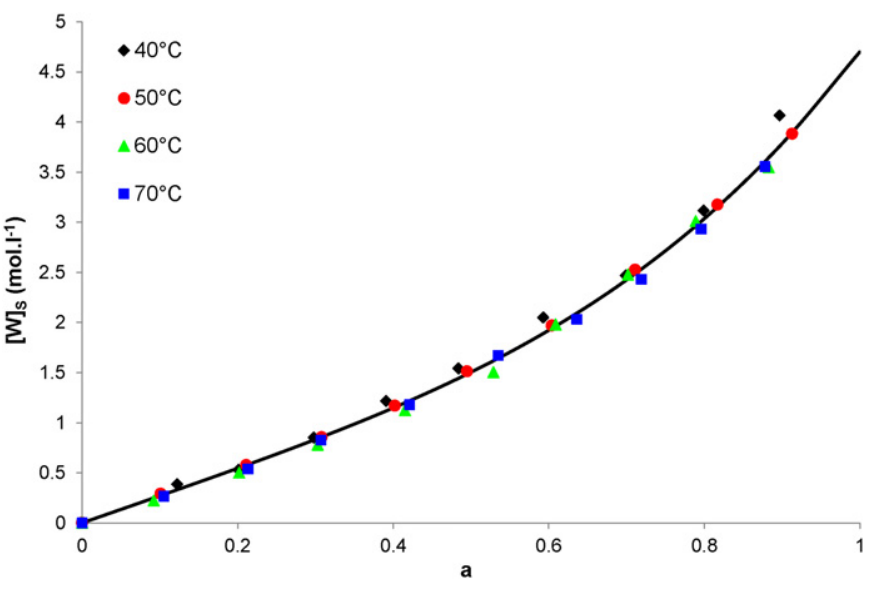

Fig. 7. Sorption Isotherms of PA 6-6 films of about $30 \mu \mathrm{m}$ thick at $40,50,60$ and $70{ }^{\circ} \mathrm{C}$ Equilibrium water concentration versus water activity in the polymer-water mixture. Simulation of all experimental data (points) by Eq. 35 (line).

$a=\frac{\mathrm{RH}}{100}$

These curves are linear between 0 and $30 \% \mathrm{RH}$, but have a negative concavity at higher $\mathrm{RH}$. Such a behaviour of Flory-Huggins type is generally observed for two very specific types of situation: when water induces an internal plasticization of a hydrophilic polymer or when water molecules associate in clusters in a hydrophobic polymer [49]. In the case of PA 6-6, it would seem that we are in the first situation $[3,6]$. Complementary tests are in progress at the laboratory in order to definitively check this assumption.

Moreover, one can notice that the equilibrium water concentration is temperature independent. This is a general behaviour for moderately polar polymers, especially for PAs. An explanation, valid for a behaviour of Henry type, but generalisable to other sorption modes, was given by Merdas et al. [50]. In these polymers, water-polymer interactions (by hydrogen bonds) are highly exothermic. Then, the heat of water dissolution is negative and its absolute value is close to the heat of water vaporization. As a result the activation energy of equilibrium water concentration, which is the sum of both previous contributions, is close to zero.

This type of sorption isotherm is generally well represented by the sum of two terms:

$[W]_{S}=H a+b a^{m}$

where $H, b$ and $m$ are constants.

In the case of PA 6-6, a satisfying adjustment of all the sorption isotherms was obtained for: $H \approx 2.7 \mathrm{~mol} \mathrm{l}^{-1}, b \approx 2.0 \mathrm{~mol} \mathrm{l}^{-1}$ and $m \approx 3.7$ (Fig. 7).

Eq. 35 was then used to determine the value of equilibrium water concentration in $100 \% \mathrm{RH}$. We have found that $[W]_{S}=4.7 \mathrm{~mol} \mathrm{l}^{-1}$, i.e. a value approximately twice lower than the initial concentration of amide groups $[E]_{0}$ (see Table 3 ).

\subsection{Calculation of the changes in molar mass}

Since each hydrolysis event leads to one chain scission, the average molar mass decreases monotonously. However, each chain scission generates two chain ends: one amine, other acid. Thus, it comes:

$$
\begin{aligned}
& {[A m]=[A c]=b_{0}+S=M_{n}^{-1}} \\
& \text { i.e. } M_{n}=\frac{1}{b_{0}+S} \\
& \text { and }
\end{aligned}
$$


Table 3

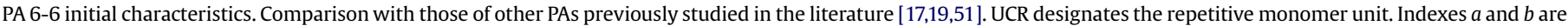
used to distinguish both types of PA 11 coming from two different suppliers.

\begin{tabular}{|c|c|c|c|c|c|c|}
\hline Polyamide & $\begin{array}{l}m_{\mathrm{UCR}} \\
\left(\mathrm{g} \mathrm{mol}^{-1}\right)\end{array}$ & $\begin{array}{l}\rho \\
\left(\mathrm{g} . \mathrm{cm}^{-3}\right)\end{array}$ & $\begin{array}{l}M_{n 0} \\
\left(\mathrm{~kg} \mathrm{~mol}^{-1}\right)\end{array}$ & $\begin{array}{l}{[E]_{0}} \\
\left(\mathrm{~mol} \mathrm{l}^{-1}\right)\end{array}$ & $b_{0}\left(\mathrm{~mol} \mathrm{l}^{-1}\right)$ & $\begin{array}{l}{[W]_{S}} \\
\left(\mathrm{~mol} \mathrm{l}^{-1}\right)\end{array}$ \\
\hline PA 6-6 & 226 & 1.14 & 18.7 & 10.1 & $6.1 \times 10^{-2}$ & 4.7 \\
\hline PA 6 [51] & 113 & 1.14 & 41.8 & 10.1 & $2.7 \times 10^{-2}$ & - \\
\hline PA 11a [19] & 183 & 1.04 & 32.7 & 5.7 & $3.2 \times 10^{-2}$ & - \\
\hline PA 11b [17] & 183 & 1.04 & 33.5 & 5.7 & $3.1 \times 10^{-2}$ & 1.0 \\
\hline
\end{tabular}

$M_{W}=\mathrm{IP} M_{n}=\frac{\mathrm{IP}}{b_{0}+S}$

where $M_{n}, M_{W}$ and IP are respectively the number and weight average molar mass and the polydispersity index after hydrolysis.

In general, for PAs:

$\mathrm{IP}=\mathrm{IP}_{0} \approx 2$

Thus, Eq. 38 can be rewritten:

$M_{W}=\frac{2}{b_{0}+S}$

The introduction of Eq. 28 into Eqs. 37 and 40 leads finally to:

$M_{n}=\frac{1}{2} M_{W}=\frac{1}{b_{0}+S_{1} \frac{1-\exp -K t}{1-\frac{S_{1}}{S_{2}} \exp -K t}}$

i.e. $M_{n}=\frac{1}{2} M_{W}=\frac{1-\frac{S_{1}}{S_{2}} \exp -K t}{b_{0}+S_{1}-\left(b_{0} \frac{S_{1}}{S_{2}}+S_{1}\right) \exp -K t}$

\subsection{Calculation of equilibrium molar masses}

Since PAs hydrolysis is reversible, the catastrophic effects of hydrolysis will continue until the establishment of an equilibrium state for which average molar masses reach an asymptotic value:

$M_{n E}=\frac{1}{2} M_{W E}=\frac{1}{b_{0}+S_{1}}$

Such equilibrium molar masses are reached when $t \rightarrow \infty$, i.e. when $S \rightarrow S_{1}$.

Now, let's consider the ratio $4 \mu / \lambda^{2}$. Using Eqs. 14 and 15 , this ratio can be expressed:

$\frac{4 \mu}{\lambda^{2}}=4 k_{C} \frac{k_{H}[W][E]_{0}-k_{C} b_{0}^{2}}{\left[k_{H}[W]+2 k_{C} b_{0}\right]^{2}}$

$\frac{4 \mu}{\lambda^{2}}=4 \frac{k_{C}[E]_{0}}{k_{H}[W]} \frac{1-\frac{k_{C} b_{0}^{2}}{k_{H}[W][E]_{0}}}{\left[1+\frac{2 k_{C} b_{0}}{k_{H}[W]}\right]^{2}}$

Considering the initial characteristics of PA 6-6 (Table 3), this equation can be rewritten: $\frac{4 \mu}{\lambda^{2}} \approx 8.6 \frac{k_{C}}{k_{H}} \frac{1-8.1 \times 10^{-5} \frac{k_{C}}{k_{H}}}{\left[1+2.6 \times 10^{-2} \frac{k_{C}}{k_{H}}\right]^{2}}$

Two extreme situations can be distinguished:

i) 1st situation: $4 \mu / \lambda^{2}<<1$, i.e. $8.6 k_{C}<<k_{H}$

Then $S_{1} \approx \frac{\lambda}{2}\left(-1+1+\frac{2 \mu}{\lambda^{2}}\right)$

i.e. $S_{1} \approx \frac{\mu}{\lambda}$

i.e. $S_{1} \approx \frac{k_{H}[W][E]_{0}-k_{C} b_{0}^{2}}{k_{H}[W]+2 k_{C} b_{0}}$

i.e. $S_{1} \approx E_{0} \frac{1-\frac{k_{C} b_{0}^{2}}{k_{H}[W][E]_{0}}}{1+\frac{2 k_{C} b_{0}}{k_{H}[W]}}$

In this situation, hydrolysis is almost complete, i.e. equilibrium is reached for a very low molar mass:

$M_{n E}=\frac{1}{2} M_{W E}=\frac{1}{b_{0}+E_{0}}$

ii) 2nd situation: $4 \mu / \lambda^{2}>1$, i.e. $k_{C}>k_{H}$

Then $S_{1} \approx \frac{\lambda}{2} \frac{2 \mu^{1 / 2}}{\lambda}$

i.e. $S_{1} \approx \mu^{1 / 2}$

i.e. $\left.S_{1} \approx \frac{k_{H}[W][E]_{0}-k_{C} b_{0}^{2}}{k_{C}}\right)^{1 / 2}$

Here, equilibrium is reached for a relatively high molar mass (close to the initial molar mass $M_{n 0}$ ):

$M_{n E}=\frac{1}{2} M_{W E}=\frac{1}{\left.b_{0}+\frac{k_{H}[W][E]_{0}-k_{C} b_{0}^{2}}{k_{C}}\right)^{1 / 2}}$ 
Table 4

Values of rate constants $k_{H}, k_{C}$ and $K$, equilibrium molar mass $M_{n E}$ and maximal number of chain scissions $S_{1}$ used for kinetic modelling in Figs. 7-12.

\begin{tabular}{|c|c|c|c|c|c|c|}
\hline Polyamide & $T\left({ }^{\circ} \mathrm{C}\right)$ & $k_{H}\left(1 \mathrm{~mol}^{-1} \mathrm{~s}^{-1}\right)$ & $k_{C}\left(1 \mathrm{~mol}^{-1} \mathrm{~s}^{-1}\right)$ & $S_{1}\left(\mathrm{~mol} \mathrm{l}^{-1}\right)$ & $K\left(\mathrm{~s}^{-1}\right)$ & $M_{n E}\left(\mathrm{~kg} \mathrm{~mol}^{-1}\right)$ \\
\hline \multirow[t]{4}{*}{ PA 6-6 } & 60 & $1.2 \times 10^{-8}$ & $1.1 \times 10^{-4}$ & $4.1 \times 10^{-2}$ & $7.0 \times 10^{-6}$ & 11.1 \\
\hline & 70 & $1.6 \times 10^{-8}$ & $1.4 \times 10^{-4}$ & $4.4 \times 10^{-2}$ & $9.3 \times 10^{-6}$ & 10.9 \\
\hline & 80 & $2.3 \times 10^{-8}$ & $1.9 \times 10^{-4}$ & $4.7 \times 10^{-2}$ & $1.3 \times 10^{-5}$ & 10.6 \\
\hline & 90 & $3.0 \times 10^{-8}$ & $2.2 \times 10^{-4}$ & $5.4 \times 10^{-2}$ & $1.7 \times 10^{-5}$ & 9.9 \\
\hline \multirow[t]{3}{*}{ PA 11a } & 110 & $2.4 \times 10^{-8}$ & $3.0 \times 10^{-5}$ & $6.0 \times 10^{-2}$ & $2.1 \times 10^{-6}$ & 11.4 \\
\hline & 120 & $4.8 \times 10^{-8}$ & $3.0 \times 10^{-5}$ & $9.0 \times 10^{-2}$ & $3.1 \times 10^{-6}$ & 8.5 \\
\hline & 140 & $8.5 \times 10^{-8}$ & $5.0 \times 10^{-5}$ & $9.3 \times 10^{-2}$ & $7.4 \times 10^{-6}$ & 8.3 \\
\hline \multirow[t]{3}{*}{ PA 11b } & 130 & $1.9 \times 10^{-8}$ & $5.3 \times 10^{-5}$ & $3.3 \times 10^{-2}$ & $3.2 \times 10^{-6}$ & 16.3 \\
\hline & 140 & $2.1 \times 10^{-8}$ & $5.3 \times 10^{-5}$ & $3.6 \times 10^{-2}$ & $3.4 \times 10^{-6}$ & 15.5 \\
\hline & 160 & $3.2 \times 10^{-8}$ & $6.8 \times 10^{-5}$ & $4.2 \times 10^{-2}$ & $5.8 \times 10^{-6}$ & 142.3 \\
\hline
\end{tabular}

The changes in molar mass obtained between 60 and $90{ }^{\circ} \mathrm{C}$ in $100 \% \mathrm{RH}$ in this study for PA 6-6, but also between 110 and $160^{\circ} \mathrm{C}$ in $100 \% \mathrm{RH}$ in the literature for PA 11 [13,14], show clearly that, for both PAs, we are in the second situation. The rate constants of hydrolysis and condensation reactions ( $k_{H}$ and $k_{C}$ respectively), the maximal number of chain scissions $\left(S_{1}\right)$ and the equilibrium molar masses $\left(M_{n E}\right)$ were determined for both PAs using Eqs. 42 and 43. The corresponding values are reported in Table 4 .

Figs. 8 and 9 show that a satisfying agreement is obtained between theory and experiment for PA 6- 6 between 60 and $90{ }^{\circ} \mathrm{C}$ in $100 \% \mathrm{RH}$.

Moreover, Fig. 10 shows that a satisfying agreement is obtained for PA 11 between theory and experiment between 110 and $160{ }^{\circ} \mathrm{C}$ in $100 \% \mathrm{RH}$.
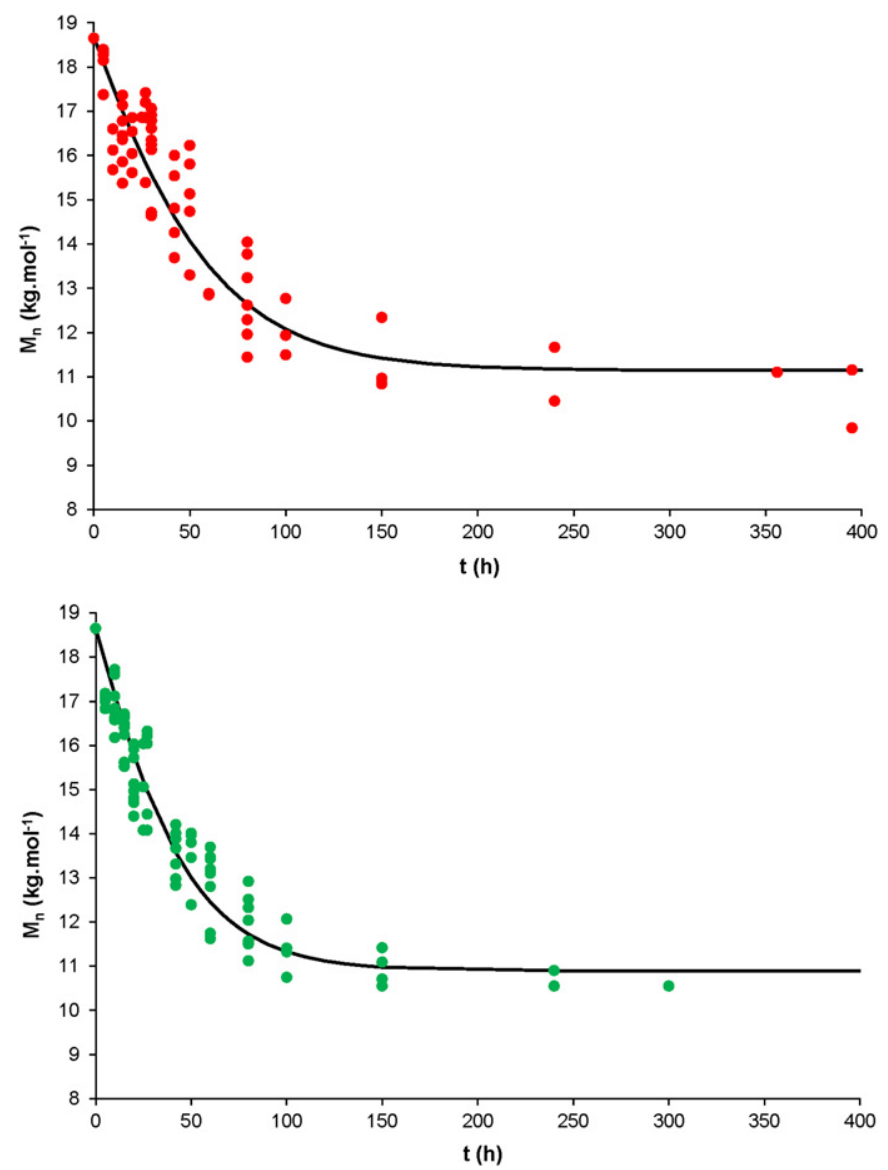

Fig. 8. Changes in number average molar mass of PA 6-6 at $60{ }^{\circ} \mathrm{C}$ (top) and $70{ }^{\circ} \mathrm{C}$ in $100 \%$ RH (bottom). Simulation of experimental data (points) by Eq. 42 (lines).
The Arrhenius parameters of rate constants $k_{H}, k_{C}$ and $K$ have been determined for both PA under study (Table 5). It is interesting to notice that the activation energies of $k_{C}$ and $K$ are almost structure independent. On the contrary, the activation energy of $k_{H}$ is significantly different between both PAs. Unfortunately, structure/ rate constants relationships are badly known in this domain. It is thus too premature to give an explanation.

\subsection{Calculation of changes in crystallinity ratio}

As illustrated by Fig. 4, chain scissions destroy the entanglement network in the amorphous phase and liberate small molecular segments which rearrange locally and initiate chemicrystallisation. Fayolle et al. [52] show that, for semi-crystalline polymers having
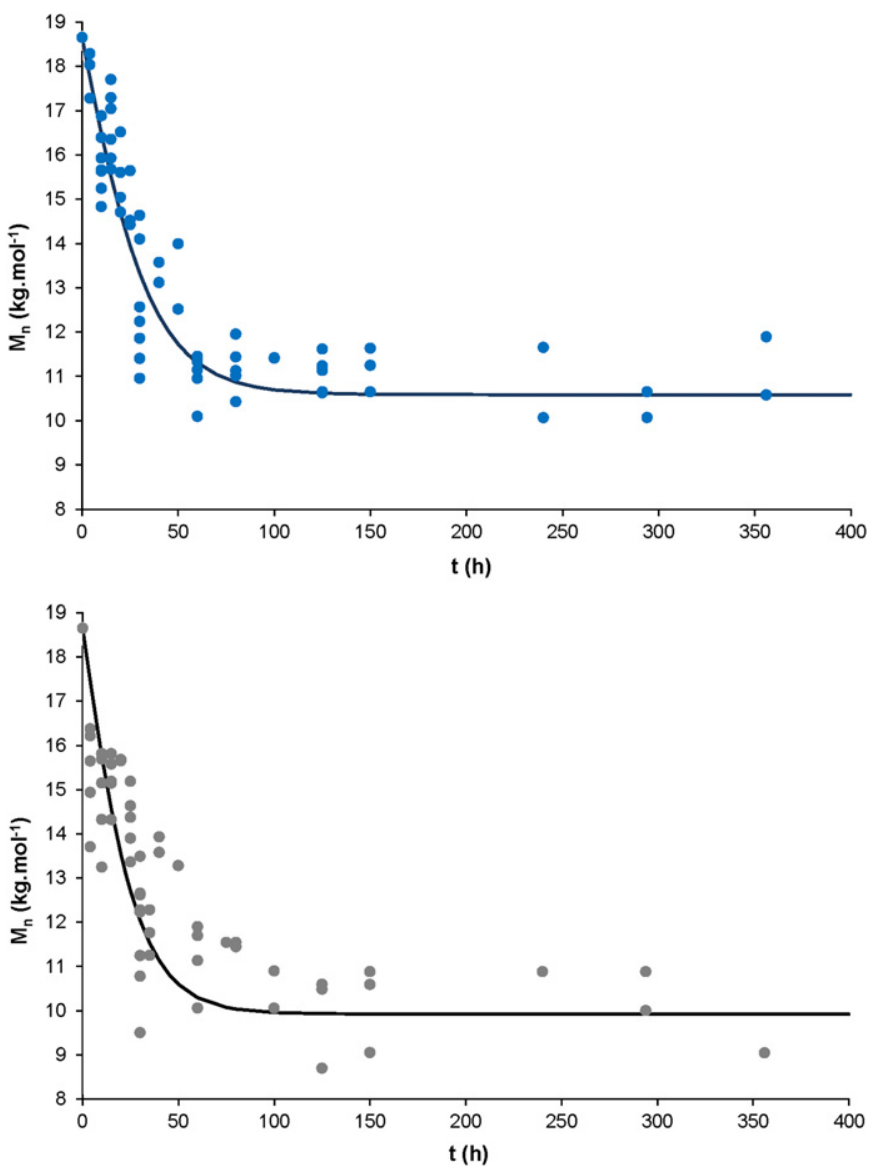

Fig. 9. Changes in number average molar mass of PA 6-6 at $80{ }^{\circ} \mathrm{C}$ (top) and $90{ }^{\circ} \mathrm{C}$ in $100 \%$ RH (bottom). Simulation of experimental data (points) by Eq. 42 (lines). 

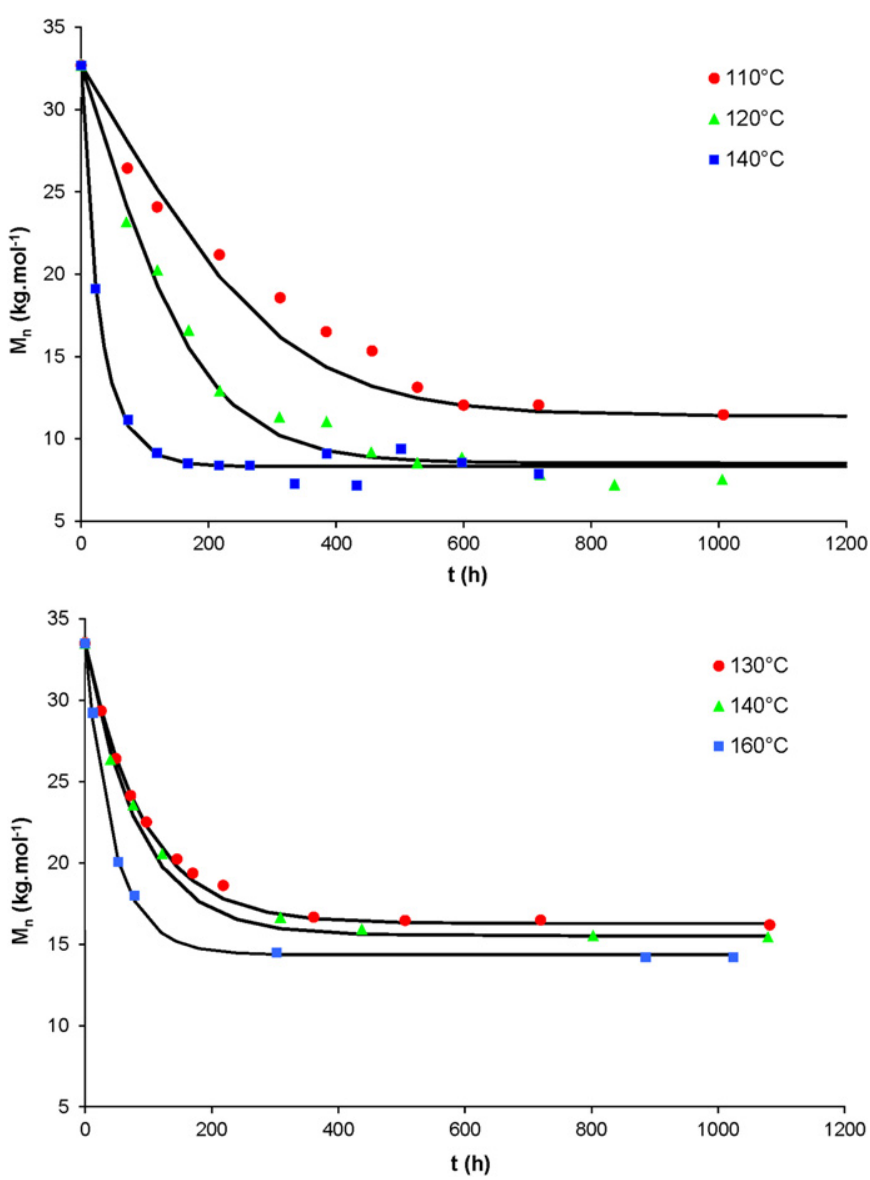

Fig. 10. Changes in number average molar mass of PA 11 at 110,120 and $140{ }^{\circ} \mathrm{C}$ (top) and 130,140 and $160{ }^{\circ} \mathrm{C}$ in $100 \% \mathrm{HR}$ (bottom). Simulation of experimental data (points) from a literature compilation $[17,19]$ by Eq. 42 (lines).

their amorphous phase in rubbery state, this increase in crystallinity can be described by a relatively simple equation:

$X_{C}=X_{C 0}+\frac{1-X_{C 0}}{\left[\left(\frac{M_{n 0}}{M_{e}}\right)^{1 / 2}-1\right]}\left[\left(\frac{M_{n 0}}{M_{n}}\right)^{1 / 2}-1\right]$

where $M_{e}$ is the entanglement threshold. In the case of PA 6-6, $M_{e}$ is of the order of $2 \mathrm{~kg} \mathrm{~mol}^{-1}$ [53].

Lim et al. [3] reported that, from the early periods of exposure in different water vapours, water induces an internal plasticization of PA 6-6, which is manifested by the transition of the physical state of amorphous phase from glassy to rubbery state. Thus, the increases in crystallinity ratio between 60 and $90{ }^{\circ} \mathrm{C}$ in $100 \% \mathrm{RH}$ for PA 6-6

Table 5

Values of rate constants, equilibrium molar mass and maximal number of chain scissions for kinetic modelling in Figs. 8-12.

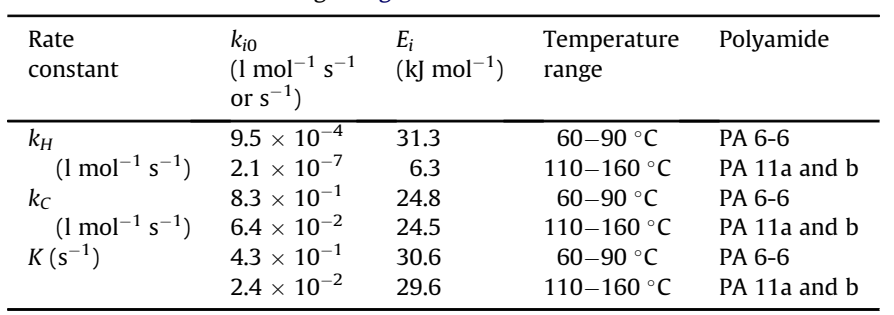

have been tentatively simulated by Eq. 58 taking $M_{e}=2 \mathrm{~kg} \mathrm{~mol}^{-1}$ Figs. 11 and 12 show a satisfying agreement between theory and experiment.

\subsection{Prediction of embrittlement}

Embrittlement of semi-crystalline polymers having initially their amorphous phase in glassy state, for instance saturated polyesters and polyamides, occurs when the average molar mass falls below a critical value $M_{n F}$ such as [54]:

$M_{n F} \approx 5 M_{e}$

In these polymers, the entanglement network allows the unwinding and drawing of chain segments located in the amorphous phase and connecting the crystalline lamellae, i.e. the plastic deformation responsible for high values of tenacity and ultimate elongation.

In the absence of entanglement network, the Van der Waals interactions are the only intermolecular forces (for cohesion). They are too low to allow the plastic deformation. In this case, we are in the presence of a brittle material of which the tenacity is about 2 or 3 decades lower than that of a ductile material.

In PA 6 and PA 11, it was found that: $M_{n F}=17 \pm 3 \mathrm{~kg} \mathrm{~mol}^{-1}$ (Table 6).

This critical value is always valid for PA 6-6. Indeed, in Fig. 13, one can see that the ultimate elongation of PA 6-6 films decreases dramatically from the early periods of exposure between 60 and $90{ }^{\circ} \mathrm{C}$ in $100 \% \mathrm{RH}$. If we choose the loss of $50 \%$ of the initial value
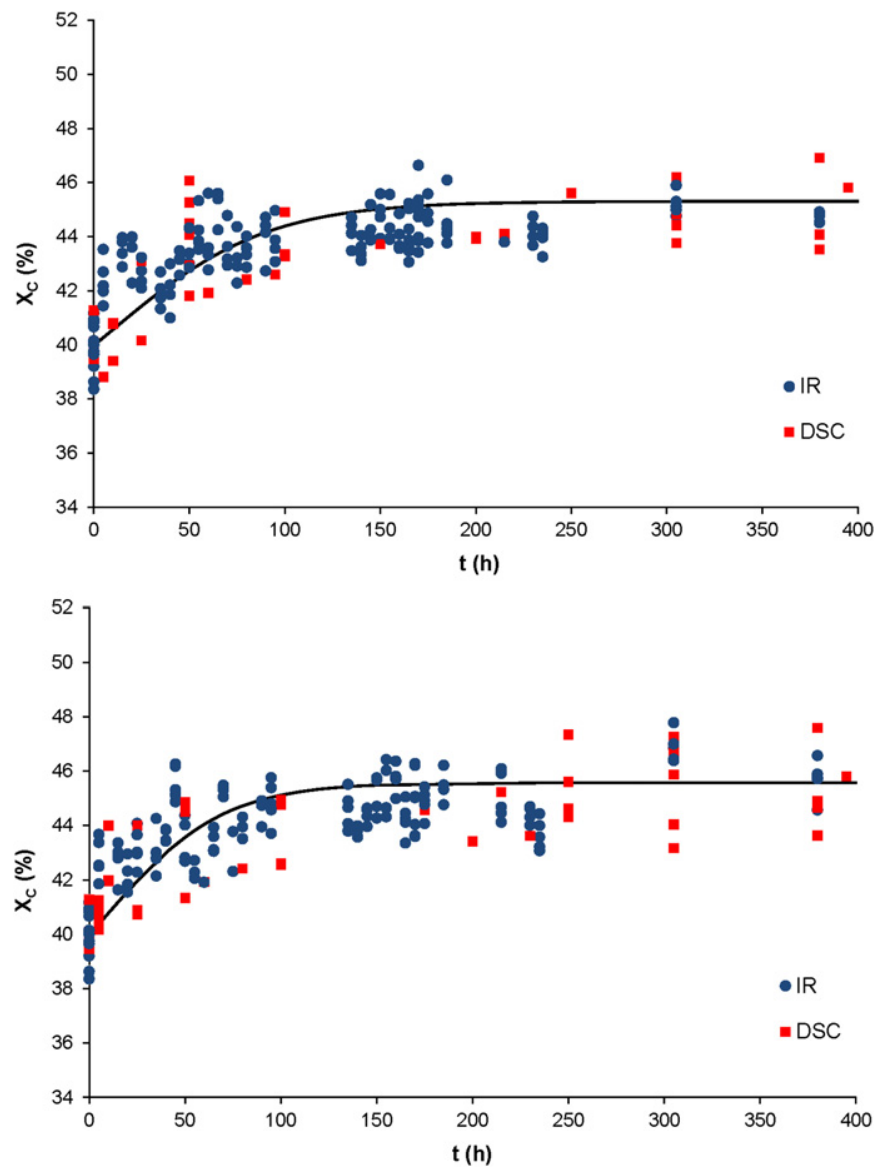

Fig. 11. Changes in crystallinity ratio of PA $6-6$ at $60{ }^{\circ} \mathrm{C}$ (top) and $70{ }^{\circ} \mathrm{C}$ in $100 \% \mathrm{HR}$ (bottom). Simulation of experimental data (points) by Eq. 58 (lines). 

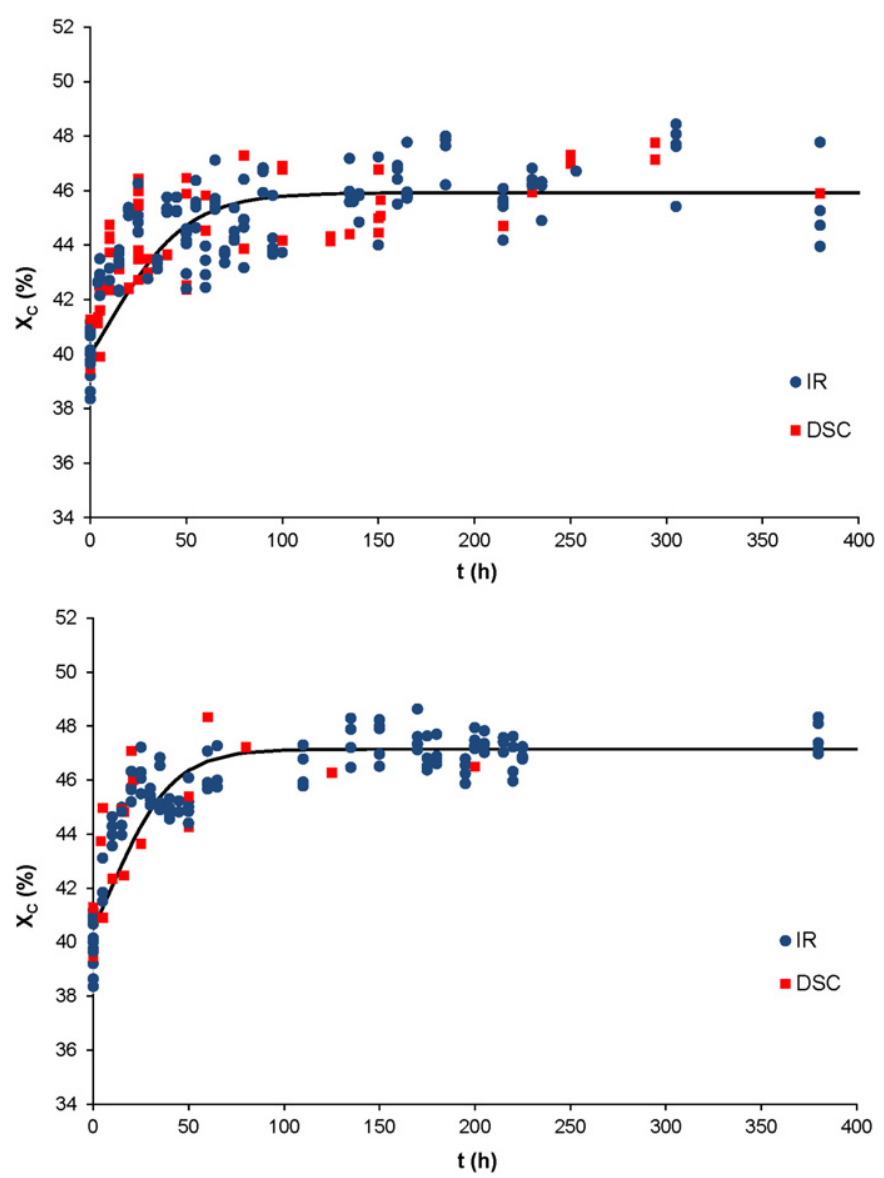

Fig. 12. Changes in crystallinity ratio of PA $6-6$ at $80{ }^{\circ} \mathrm{C}$ (top) and $90{ }^{\circ} \mathrm{C}$ in $100 \% \mathrm{HR}$ (bottom). Simulation of experimental data (points) by Eq. 58 (lines).

of ultimate elongation as end-life criterion, as usually practiced in industry, we obtain a critical value of the order of $M_{n F}=17 \pm 1 \mathrm{~kg} \mathrm{~mol}^{-1}$.

Expression of time for embrittlement $t_{F}$ can be obtained from Eq. 42 :

$\left\{\frac{S_{1}}{S_{2}}-M_{n}\left(b_{0} \frac{S_{1}}{S_{2}}+S_{1}\right)\right\} \exp -K t=1-M_{n}\left(b_{0}+S_{1}\right)$

i.e. $\exp -K t=\frac{S_{2}}{S_{1}} \frac{1-M_{n}\left(b_{0}+S_{1}\right)}{1-M_{n}\left(b_{0}+S_{2}\right)}$

i.e. $t=-\frac{1}{K} \operatorname{Ln}\left[\frac{S_{2}}{S_{1}} \frac{1-M_{n}\left(b_{0}+S_{1}\right)}{1-M_{n}\left(b_{0}+S_{2}\right)}\right]$

i.e. $t=-\frac{1}{k_{C}\left(S_{1}-S_{2}\right)} \operatorname{Ln}\left[\frac{S_{2}}{S_{1}} \frac{1-M_{n}\left(b_{0}+S_{1}\right)}{1-M_{n}\left(b_{0}+S_{2}\right)}\right]$

Table 6

Embrittlement criterion and equilibrium molar mass of PA 6-6. Comparison with values of two other PAs previously studied in the literature [7,51,55].

\begin{tabular}{lll}
\hline Polyamide & $M_{n F}\left(\mathrm{~kg} \mathrm{~mol}^{-1}\right)$ & $M_{n E}\left(\mathrm{~kg} \mathrm{~mol}^{-1}\right)$ \\
\hline PA 6-6 & $17 \pm 1$ & $10 \pm 1$ \\
PA 6 & $17 \pm 3[51,55]$ & - \\
PA 11 & $17 \pm 2[7]$ & $12 \pm 4$ \\
\hline
\end{tabular}

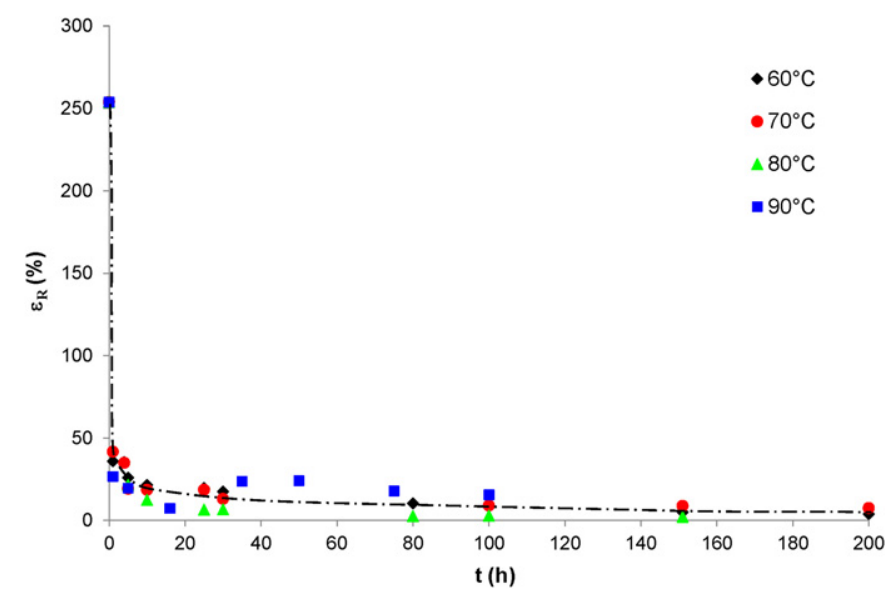

Fig. 13. Changes in ultimate elongation of PA 6-6 films at $60,70,80$ and $90{ }^{\circ} \mathrm{C}$ in $100 \%$ HR.

As a result, embrittlement happens when $M_{n}=M_{n F}$, i.e. when:

$t_{F}=-\frac{1}{k_{C}\left(S_{1}-S_{2}\right)} \operatorname{Ln}\left[\frac{S_{2}}{S_{1}} \frac{1-M_{n F}\left(b_{0}+S_{1}\right)}{1-M_{n F}\left(b_{0}+S_{2}\right)}\right]$

\section{Conclusions}

A general kinetic model has been developed for describing reversible hydrolysis not controlled by water diffusion. Its validity has been successfully checked from the changes in molar mass between 60 and $90{ }^{\circ} \mathrm{C}$ in 100\% RH for PA 6-6, but also between 110 and $160{ }^{\circ} \mathrm{C}$ in $100 \% \mathrm{RH}$ for PA 11 . Moreover, a structural embrittlement criterion $M_{n F}=17 \pm 1 \mathrm{~kg} \mathrm{~mol}^{-1}$ has been introduced into the kinetic model for predicting the time for embrittlement. This latter would be PA structure independent.

At this stage, two interesting prospects can be considered:

- The use of kinetic model as an inverse method in order to determine the rate constants of hydrolysis and condensation reactions, and to study structure/rate constant relationships in polymers containing hydrolysable groups, for instance: amide (polyamides, polyurethanes, etc.), ester (polyesters, polycarbonates, anhydride crosslinked epoxies, etc.) or imide groups (polyimide).

- The coupling of this model with common commercial models for mechanical calculation in order to predict the failure of PA parts in use conditions.

\section{References}

[1] Hernandez RJ. Effect of water vapour on the transport properties of oxygen through polyamide packaging materials. J Food Eng 1994;22:495-504.

[2] Hernandez RJ, Gavara R. Sorption and transport of water in nylon 6 films. J Polym Sci Part B Polym Phys 1994;32:2367-74.

[3] Lim L-P, Britt IG, Tung MA. Sorption and transport of water vapor in nylon 6-6 films. J Appl Polym Sci 1999;71:197-206.

[4] Khanna YP, Khun WP, Sichina WJ. Reliable measurements of the Nylon 6 glass transition made possible by the new dynamic DSC. Macromolecules 1995; 28(8):2644-6.

[5] Fraenkel HA, Kagan VA. Effects of moisture conditioning methods on mechanical properties of injection molded Nylon 6. J Reinforc Plast Compos 2004;23(7):729-37.

[6] Okajima K, Yamane C, Ise F. Polymeric encyclopedia. In: Salamone J, editor. Boca Raton: CRC Press; 1996.

[7] Atofina technical report. Thermoplastic polymers for off-shore flexible pipes. Atofina Technical Polymers Division; February 2002. 
[8] Heikens D, Hermans PH, Veldhoven HA. Kinetics of the acid hydrolysis of cyclic oligomers from nylon 6 and nylon 6-6. Makromol Chem 1959;30: 154-68.

[9] Williams A. Dilute acid-catalyzed amide hydrolysis: efficiency of N-protonation mechanism. J Amer Chem Soc 1976;98(18):5645-51.

[10] McClelland RA. Kinetics and mechanism of amide acetal hydrolysis. Carbonoxygen vs. carbon-nitrogen bond cleavage in acid solutions. J Amer Chem Soc 1978;100(6):1844-9.

[11] Modro TA, Yates K, Beaufays F. Transitio state activity coefficients in the acidcatalyzed hydrolyses of amides. Can J Chem 1977;55:3050-7.

[12] Cox RA, Yates K. The hydrolyses of benzamides, methylbenzimidatium ions and lactams in aqueous sulfuric acid. The excess acidity method in the determination of reaction mechanisms. Can J Chem 1981;59:2853-63.

[13] Serpe G, Chaupart N, Verdu J. Ageing of polyamide 11 in acid solutions. Polymer 1997;38(8):1911-7.

[14] Chaupart N, Serpe G, Verdu J. Molecular weight distribution and mass changes during polyamide hydrolysis. Polymer 1998;39(6-7):1375-80.

[15] Meyer A, Jones N, Lin Y, Kranbuehl D. Characterizing and modelling the hydrolysis of polyamide 11 in a pH 7 water environment. Macromolecules 2002;35:2784-98.

[16] Jacques B, Werth M, Merdas I, Thominette F, Verdu J. Hydrolytic ageing of polyamide 11 - hydrolysis kinetics in water. Polymer 2002;43:6439-47.

[17] Merdas I, Thominette F, Verdu J. Hydrolytic ageing of polyamide 11 - effect of carbon dioxide on polyamide 11 hydrolysis. Polym Degrad Stab 2003;79:419-25.

[18] Cribbs D, Ogale AA. Hydrolytic degradation of nylon 6-6 pile carpet fibres. Textile Res J 2003;73(2):98-104.

[19] Romao W, Castro EVR, Filho EAS, Guimaraes RCL, Silva ANL, Teixeira SCS, et al Aging of polyamide 11 used in the manufacture of flexible piping. J Appl Polym Sci 2009; 114:1777-83.

[20] Thomason. Structure-property relationships in glass-reinforced polyamide. Part 3: effects of hydrolysis ageing on the dimensional stability and performance of short glass-fiber-reinforced polyamide 66. Polym Compos 2007;28: 344-54.

[21] Alam TM. Solution ${ }^{17} \mathrm{O}$ NMR study of thermal hydrolysis in nylon 6-6. Polymer 2003;44:6531-6.

[22] Bernstein R, Derzon DK, Gillen KT. Nylon 6.6 accelerated aging studies: thermal oxidative degradation and its interaction with hydrolysis. Polym Degrad Stab 2005;88:480-8.

[23] Bernstein R, Gillen KT. Nylon 6.6 accelerating aging studies: II. Long-term thermal-oxidative and hydrolysis results. Polym Degrad Stab 2010;95: 1471-9.

[24] Johnson W. Invitation to organic chemistry. Sudbury: Jones and Bartlett Publishers; 1999.

[25] Clayden J, Greeves N, Warren S, Wothers P. Organic chemistry. Oxford University Press; 2001.

[26] Fettes EM. Chemical reactions of polymers. New York: Interscience Wiley Publishers; 1964

[27] Moiseev YuV, Zaikov GE. Chemical resistance of polymers in aggressive media. New York: Springer Verlag; 1987.

[28] Colin X, Verdu J. Thermooxidative and thermohydrolytic aging of organic composite matrices. In: Song DB, editor Resin composites: properties, production and applications. New York: Nova Science Publishers; 2011. p. 255-98. Chap. 8.

[29] Colin X, Verdu J. “Ageing of organic matrix composite materials”, in Wiley encyclopedia of composites, 2nd Edition, Nicolais L, Borzacchiello A and Lee S.M eds, John Wiley \& Sons Ltd, New York, in press.

[30] Challis BC, Challis J. In: Zabicky J, editor. The chemistry of amides. London: Wiley-Interscience; 1970.
[31] Kohan MI. Nylon plastics handbook. New York: Hanser Gardner Publishers; 1995.

[32] Deopura BL, Alajirusami R, Joshi M, Gupta B. Polyesters and polyamides. Cambridge: Woodhead Publishing; 2008.

[33] Braestrup M, Andersen JB, Andersen LW, Bryndum M, Christensen CJ, Rishoj N. Design and installation of marine pipelines. Oxford: ASME \& Blackwell Science Ltd; 2005.

[34] Mikolajewski E, Swallow JE, Webb MW. Wet oxidation of undrawn nylon 66 and model amides. J Appl Polym Sci 1964;8(5):2067-93.

[35] Gonçalves ES, Poulsen L, Ogilby PR. Mechanism of the temperature dependent degradation of polyamide 6-6 films exposed to water. Polym Degrad Stab 2007;92(11):1977-85.

[36] Zimmerman J. In: Mark HF, Bikales NM, Overberger CG, Menges G, Kroschwitz JI, editors. Encyclopedia of polymer science an engineering. 2nd ed. New York: John Wiley and Sons; 1987.

[37] Holland B, Hay J. Thermal degradation of nylon polymers. Polym Intern 2000; 49(9):943-8.

[38] Elsein T, Brogly M, Schultz J. Crystallinity measurement of polyamides absorbed as thin films. Polymer 2002;43:4811-22.

[39] Hummel DO. Infrared spectra of polymers. New York: Wiley; 1966.

[40] Vasanthan N, Salem D. Infrared spectroscopic characterization of oriented polyamide 6-6: Band assigment and crystallinity measurement. J Polym Sci Part B Polym Phys 2000;38:516-24.

[41] Starkweather HW, Moynihan RE. Density, infrared absorption and crystallinity in 6-6 nylon and 6-10 nylon. J Polym Sci 1956;22(102):363-8.

[42] Arimoto H. $\alpha-\gamma$ transition of nylon 6. J Polym Sci Part A Gen Pap 1964;2(5): 2283-95.

[43] Jakes J, Krimm S. Valence forcé field for amide group. Spectrochim Acta A $1971 ; 27(1): 19-34$

[44] Murthy N, Bray R, Curran S, McDonald M. A guide to material characterization and analysis. In: Sibilia J, editor. New York: Wiley; 1994

[45] Thanki PN, Singh RP. Photo-oxidative degradation of nylon 6-6 under accelerated weathering. Polymer 1998;39:6363-7.

[46] Vasanthan N, Murthy NS, Bray RG. Investigation of brill transition in nylon 6 and nylon 6-6 by infrared spectroscopy. Macromolecules 1998;31(23): 8433-5.

[47] Bueche F. Viscosity, self-diffusion and allied effects in solid polymers. J Chem Phys 1952;20(12):1959-64.

[48] Bueche F. The viscoelastic properties of plastics. J Chem Phys 1954;22(4): 603-9.

[49] Naylor TV. Permeation properties. In: Comprehensive polymers science, vol. 2. Pergamon Press; 1989. p. 643-68.

[50] Merdas I, Thominette F, Verdu J. "Humid aging of polyetherimide. I. Water sorption characteristics. J Appl Polym Sci 2000;77:1439-44.

[51] Dong W, Gijsman P. Influence of temperature on the thermo-oxidative degradation of polyamide 6 films. Polym Degrad Stab 2010;95(6): 1054-62.

[52] Fayolle B, Richaud E, Colin X, Verdu J. Review: degradation-induced embrittlement in semi-crystalline polymers having their amorphous phase in rubbery state. J Mater Sci 2008;43:6999-7012.

[53] Wu S. Chain structure and entanglement. Polym Sci Part B Polym Phys 1989; 27(4):723-41.

[54] Kausch HH, Heymans N, Plummer CJ, Decroly P. Matériaux polymères. Propriétés mécaniques et physiques. Principes de mise en œuvre. Lausanne: Presses Polytechniques et Universitaires Romandes; 2001. pp. 249.

[55] Frosstrom D, Terselius B. Thermo-oxidative stability of polyamide 6 films. I. Mechanical and chemicals characterisation. Polym Degrad Stab 2000;67: $69-78$ 